\title{
ROENTGEN STEREOPHOTOGRAMMETRIC ANALYSIS AS A PREDICTOR OF MECHANICAL LOOSENING OF KNEE PROSTHESES
}

\begin{abstract}
LEIF RYD. BJÖRN E. J. ALBREKTSSON, LARS CARLSSON, FINN DANSGÅRD, PETER HERBERTS. ANDERS LINDSTRAND, LARS REGNÉR, SØREN TOKSVIG-LARSEN
\end{abstract}

From the University of Lund, Sweden

The tibial components in 143 patients with total knee replacements performed before 1988 were assessed for micromotion using roentgen stereophotogrammetric analysis (RSA) over a period of 13 years. The fixation of the prostheses remained clinically sound in all cases, although revision had been required for other reasons in seven.

In a second group taken from all cases with RSA available on our full database to 1990, 15 tibial components had been followed by RSA from the insertion until, 1 to 11 years after the initial arthroplasty, they were revised for mechanical loosening of the tibial component; 12 of these comprised all the loosenings in the base group, thus making a total of 155 consecutive cases, while an additional three were inserted after the base material had been compiled.

The mean migration in the first group was about $1 \mathrm{~mm}$ at one year, but subsequent migration was slower, reaching a mean of about $1.5 \mathrm{~mm}$ after ten years. About one-third migrated continuously throughout follow-up, while two-thirds ceased to migrate after one to two years.

In the revision group, 14 components had migrated continuously and at one year significantly more than

\footnotetext{
L. Ryd. Associate Professor

A. Lindstrand, Associate Professor

S. Toksvig-Larsen, Senior Orthopaedic Registrar

Department of Orthopaedics

F. Dansgård. Registrar

Department of Diagnostic Radiology

University Hospital, S-221 85 Lund, Sweden.

L. Carlsson, Associate Professor

P. Herberts

L. Regnér. Professor

Department of Orthopaedics, Sahlgrenska University Hospital. S-413 457 Göteborg. Sweden.
}

B. E. J. Albrektsson. Consultant Orthopaedic Surgeon

Department of Orthopaedics, Centrallasadrettet, S-501 15 Borås, Sweden

Correspondence should be sent to Dr L. Ryd.

(1)1995 British Editorial Society of Bone and Joint Surgery

$0301-620 \mathrm{X} / 95 / 3974 \$ 2.00$ those in the first group. One revision case lacked the crucial one-year follow-up and could not be classified.

These findings suggest that mechanical loosening begins early in the postoperative period. Clinical symptoms which necessitate revision, seen at this stage in $20 \%$ of abnormally migrating tibial components, may not appear until up to ten years after the operation. RSA can be used at one to two years to identify prostheses 'at risk' of loosening with a predictive power of about $85 \%$.

J Bone Joint Surg [Br] 1995:77-B:377-83.

Received 16 June 1994: Accepted 14 September 1994

The fixation of joint implants to bone remains a clinical and scientific challenge. Clinically, prosthetic components continue to loosen (Rand et al 1987; Albrektsson and Herberts 1988; Nafei et al 1992) and research to improve prosthetic fixation continues (Miller et al 1979; Lidgren, Bodelind and Möller 1987; Cook and Thomas 1988; Geesink, De Groot and Klein 1988; Ranawat, Rawlins and Harju 1989; Miura et al 1990; Toksvig-Larsen. Ryd and Lindstrand 1990; Søballe et al 1991).

The shortcomings of conventional radiography have made monitoring of the fixation of prostheses and of the effects of implementation of new techniques of fixation difficult and imprecise (Ahlberg and Lindén 1977; Blaha et al 1982; Ryd et al 1983; Tibrewal, Grant and Goodfellow 1984; Albrektsson and Herberts 1988). In recent years, studies on prosthetic fixation using roentgen stereophotogrammetric analysis (RSA) have been published (Ryd et al 1983, 1990; Mjöberg et al 1985; Snorrason and Kärrholm 1990; Nilsson et al 1991). Although of theoretical interest, these have not yet established that observations made by RSA correlate with the clinical evidence of mechanical loosening. It has been noted that virtually all tibial components migrate during the initial period but in most cases this movement ceases after one year. Some prostheses continue to migrate; such continuous migration may indicate future loosening (Ryd et al 1990).

To establish the role of RSA in the study of this problem we have compared the migratory pattern of well-functioning prostheses with that of a group which had eventually to 
be revised for mechanical loosening. We also tried to determine whether RSA at two years could serve as a predictive test for future loosening (Ryd et al 1990).

\section{PATIENTS AND METHODS}

We identified two groups of patients from approximately 450 with knee arthroplasties who had been marked with tantalum beads for RSA in Lund since 1978 and in Göteborg between 1982 and 1990.

The first group, the base material, consisted of 175 patients in whom arthroplasty had been performed between 1979 and 1983 in Lund and between 1982 and 1988 in Göteborg. All these cases had been entered into the RSA database from the onset up to the time when new projects were started at both centres. At the time of assessment 37 patients had died; none had experienced any problem with the prostheses and data for these cases were included up to the time of death. Patients followed up for less than two years were excluded, as were a number in whom technical difficulties, such as faulty placement of the tantalum markers, unstable tantalum markers, or technically inadequate radiographs, were encountered. In all, 32 cases were excluded, leaving 143 in this group for the final analysis. None had had mechanical loosening of the tibial component, although seven had been revised for wear (3), loosening of the femoral component (2) and contralateral arthritis (2). In all these patients the tibial component had been found to be securely bonded to the bone at revision and no movement of the prosthesis could be induced. The histological fea- tures of three of these interfaces have been published previously (Ryd and Linder 1989). No further cases were excluded from this consecutive series and the mean followup was seven years.

The second group, the revision group, consisted of the 15 cases in the RSA database which had been revised for mechanical loosening of the tibial component. Of these, 12 had been inserted during the period of compilation of the larger first group and would have belonged there had they not loosened. The three other cases had their prostheses inserted later. In all cases mechanical loosening was confirmed at revision, 1 to 11 years after the initial arthroplasty.

Of the 158 cases studied, 109 had been operated on in Lund and 49 in Göteborg. The prostheses which were used represent the evolution of knee arthroplasty during the 15 years of the study. The diagnosis, age and gender distributions were similar in both groups (Table I).

RSA, as described by Selvik (1974), was used to study micromotion. At operation, the tibial component and the tibia were each labelled with four to six tantalum markers. Soon after operation, before the patients were mobilised, a reference RSA examination was carried out and stereograms obtained with the knee inside a calibration cage. Subsequently, RSA examinations were undertaken at 6 to 12 weeks, 6 months, 1 year, 2 years and then at intervals of 2 years. The stereograms were digitised using a highprecision tablet (Hasselblad Engineering, precision $<20 \mu \mathrm{m}$ ). Transformation from 2-D to 3-D co-ordinates and subsequent kinematic analysis were done by computer

Table I. Details of the two groups of patients and the prostheses used

\begin{tabular}{|c|c|c|c|c|}
\hline \multirow[b]{2}{*}{ Prosthesis } & \multirow[b]{2}{*}{ Mean age (yr) } & \multirow[b]{2}{*}{ Male:female } & \multicolumn{2}{|c|}{ Diagnosis* } \\
\hline & & & $\overline{\mathbf{O A}}$ & $\mathbf{R A}$ \\
\hline \multicolumn{5}{|l|}{ Base group } \\
\hline $\begin{array}{l}\text { Total condylar } \\
(\mathrm{n}=27)\end{array}$ & 71 & $5: 22$ & 27 & 0 \\
\hline $\begin{array}{l}\text { Kinematic } \\
(n=7)\end{array}$ & 75 & $1: 6$ & 7 & 0 \\
\hline $\begin{array}{l}\text { PCA total } \\
\qquad(n=33 t)\end{array}$ & 68 & $6: 27$ & 20 & 13 \\
\hline $\begin{array}{l}\text { Freeman-Samuelson } \\
\qquad(\mathrm{n}=32 \ddagger)\end{array}$ & 66 & $6: 26$ & 15 & 17 \\
\hline Marmor $(n=23)$ & 69 & $2: 21$ & 23 & 0 \\
\hline Lund prototype $(n=14)$ & 71 & $2: 12$ & 14 & 0 \\
\hline Miller-Galante $(n=7)$ & 68 & $2: 5$ & 7 & 0 \\
\hline Total $=143$ & 69 & $24: 119$ & 113 & 30 \\
\hline \multicolumn{5}{|l|}{ Revision group } \\
\hline $\begin{array}{l}\text { PCA total } \\
(n=4) \S\end{array}$ & 64 & $3: 1$ & 3 & 1 \\
\hline $\begin{array}{l}\text { Freeman-Samuelson } \\
\qquad(\mathrm{n}=10) 9\end{array}$ & 63 & $2: 8$ & 4 & 6 \\
\hline Marmor $(n=1)$ & 64 & $0: 1$ & 1 & 0 \\
\hline Total $=15$ & 63 & $5: 10$ & 8 & 7 \\
\hline
\end{tabular}

* OA, osteoarthritis; RA, rheumatoid arthritis

$\dagger 20$ cemented, 13 non-cemented

$\ddagger 6$ cemented, 26 non-cemented, 16 all-polyethylene, 16 metal-backed

$\$$ all cemented

I 1 cemented, 9 non-cemented, 5 all-polyethylene, 5 metal-backed 
data processing using Euler rigid body kinematics. The data were obtained as rotation and translation along the three cardinal axes which coincided with the principal anatomical planes of the body. The 3-D vector of the prosthetic marker which moved the most, the maximum total point motion (MTPM), was also given. This value is a threedimensional vector without a direction representing the magnitude of the migration only, and it must be emphasised that MTPM is not equivalent to subsidence. The accuracy of RSA as applied to knee arthroplasty has been determined to be $0.2 \mathrm{~mm}$ (Ryd 1986).

To analyse the pattern of migration, the material was subdivided into categories of stable and migrating prostheses according to two different criteria. Any patient with a nominal MTPM $>200 \mu \mathrm{m}$ at any follow-up after one year was allocated to the group showing strict continuous migration (SCM), while prostheses not fulfilling this criterion were stable. A prosthesis showing fast migration after the one-year follow-up was allocated to the modified continuous migration (MCM) group while cases continuing to migrate only slowly were classified as stable. The criterion for fast migration was set to greater than the mean minus $1 \mathrm{SD}$ of all the cases in the revision group. Analysis of the revision group showed this value to be approximately $0.2 \mathrm{~mm} / 2$ years. Thus, cases migrating at a higher rate fulfilled the MCM criteria while those migrating at a lower rate were classified as stable. A total of 909 RSA examinations form the basis of this study. Technical difficulties with RSA and the failure of patients to attend for follow-up resulted in the loss of 118 potential RSA recordings.

Conventional radiography using whole-leg films was used to determine the mechanical axis of the leg (Odenbring, Berggren and Peil 1993). A value of $<180^{\circ}$ denoted a varus knee. The position of the tibial component relative to the long axis of the tibia in both the anteroposterior and the lateral views was also assessed (Ryd et al 1983).

\section{RESULTS}

In the base material every tibial component, except one of the Miller-Galante type, showed some migration, mostly during the first year. Using the SCM criteria, $48 \%$ ceased to migrate after one year, while $52 \%$ continued to do so. Using the more lenient definition of MCM, 33\% continued to migrate while $66 \%$ remained stable after one year (Fig. 1). The mean MTPM for the group showing initial migration was smaller at six months than that for the group showing continuous migration, whether defined as SCM (Mann-Whitney U test, p < 0.02) or as MCM ( $\mathrm{p}<0.004)$.

Further analysis showed a difference between cemented and non-cemented components, with the latter migrating significantly more during the first year, reaching a mean of about $1.7 \mathrm{~mm}$. The cemented components had a mean migration of $0.7 \mathrm{~mm}$ (Mann-Whitney $U$ test, $p<0.0001$; Fig. 2).

The direction of migration was erratic. The entire base

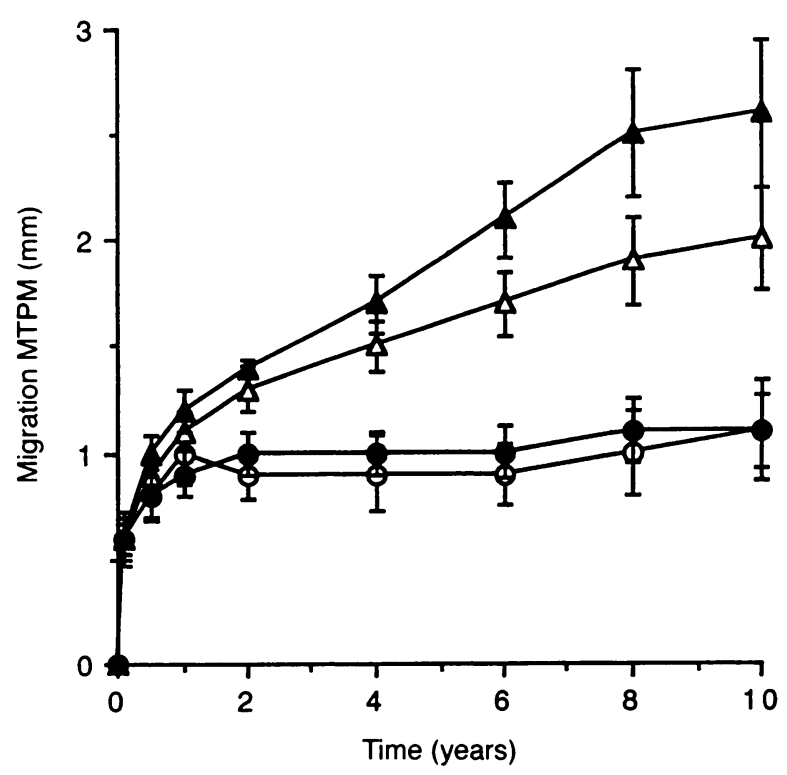

Fig. 1

Diagram showing migration (mean \pm SEM) of 143 tibial components which were not revised for mechanical loosening. Triangles represent continuously migrating prostheses, circles stable ones. Open characters denote the SCM criteria, filled characters the MCM criteria (see text). (Few prostheses were followed for more than ten years and these data were excluded.)

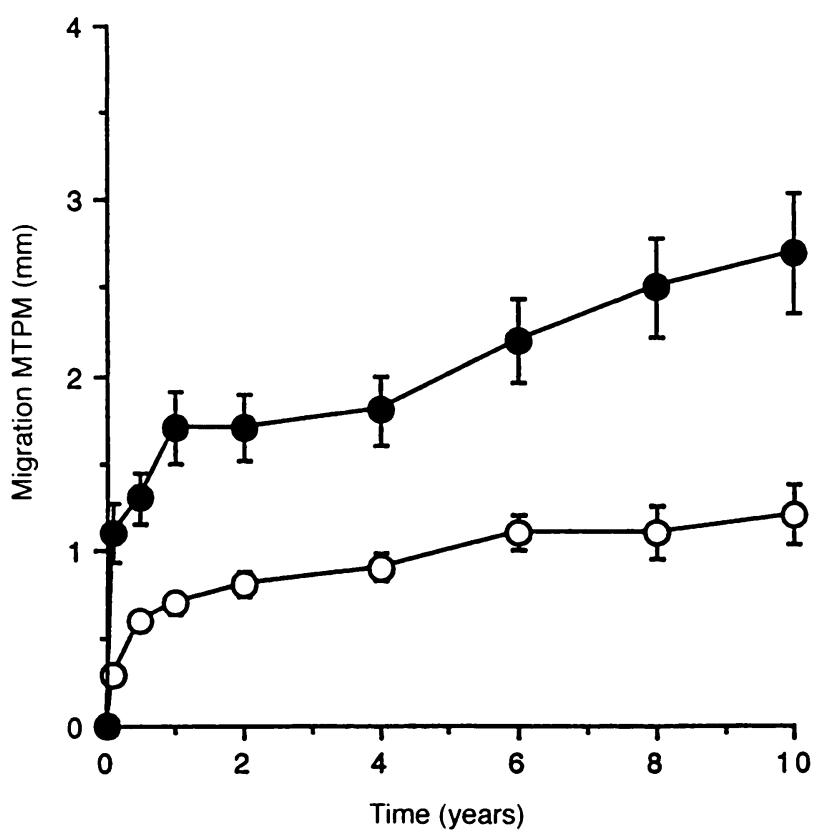

Fig. 2

Diagram representing the migration of 97 cemented (open circles) and 46 non-cemented (filled circles) tibial components which were not revised for mechanical loosening. 


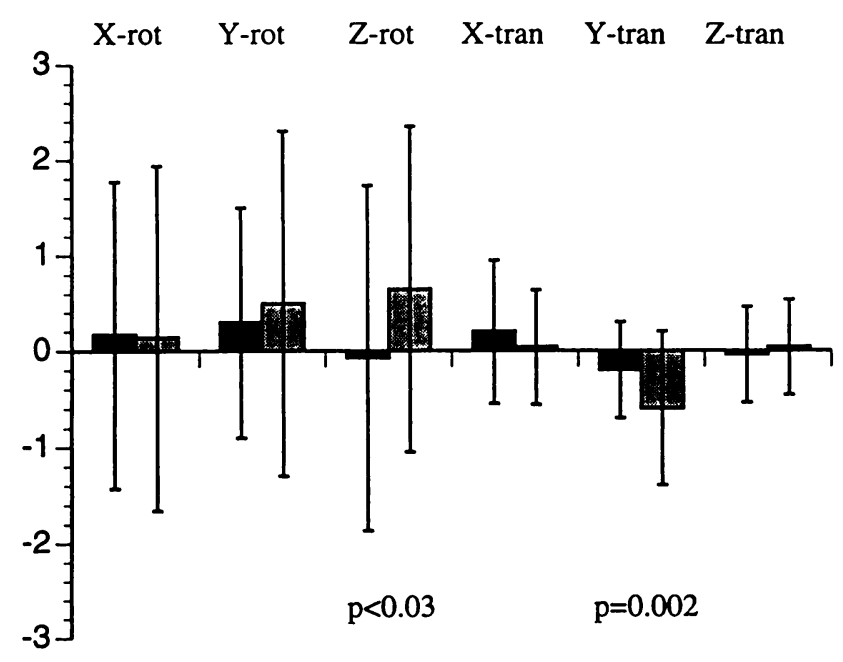

Fig. 3

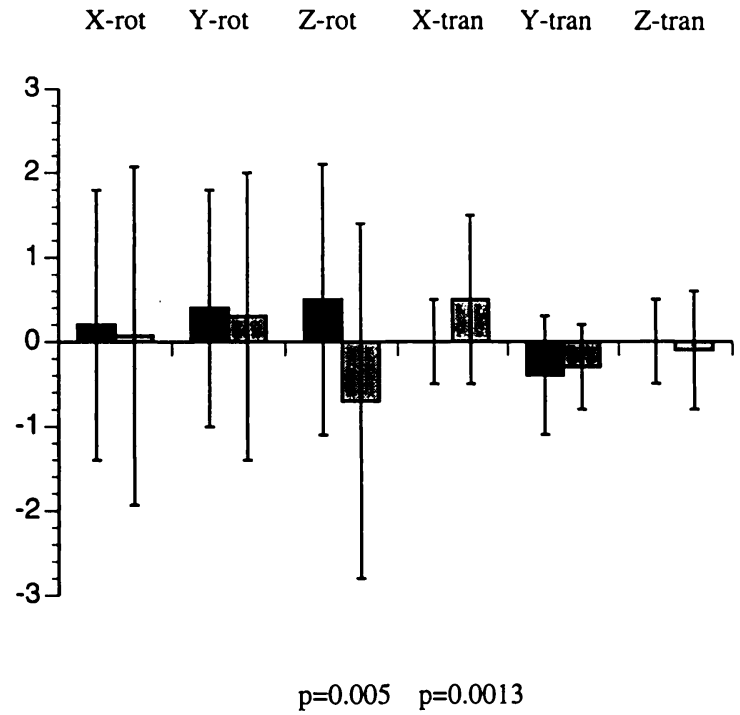

Fig. 4

46 non-cemented (grey bars) tibial components which were not revised for mechanical loosening. The axis is transverse and $a+$ sign denotes anterior tilt or lateral translation. The Y-axis is vertical and + sign denotes outward rotation or upward translation. The $\mathrm{Z}$-axis is sagittal and a + sign denotes varus tilt (peripheral tilt for unicompartmental cases) and anterior translation.

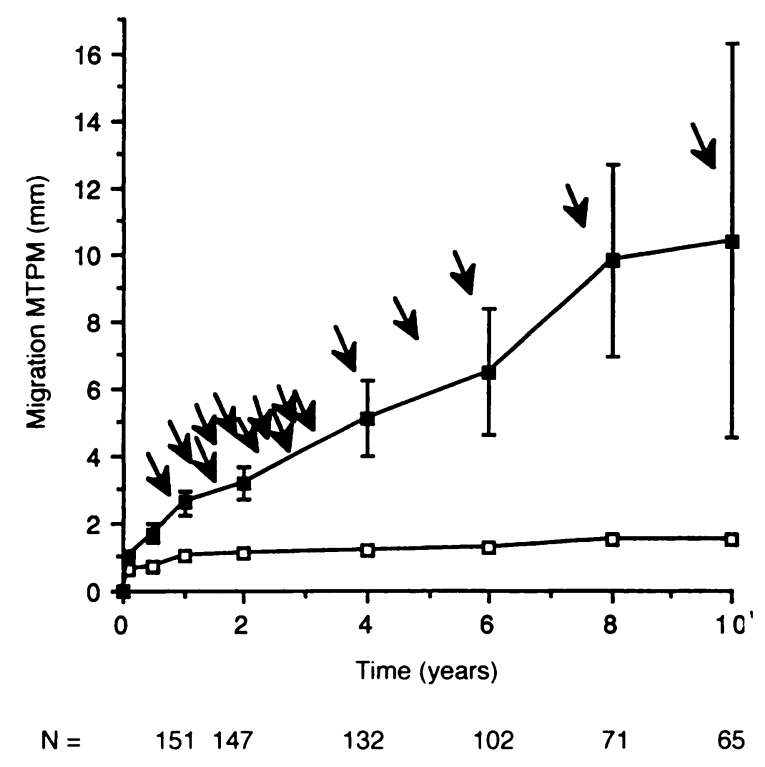

Fig. 5

Diagram representing the migration of 143 tibial components (open squares) which were not revised and 15 tibial components (filled squares) which were revised for mechanical loosening. Arrows indicate the point in time when the arthroplasty became symptomatic. Each of the revisions was performed within a year from this time.

material showed some outward rotation about the vertical axis and subsidence along the vertical axis, but with considerable scatter in both directions. Subsidence, of a mean of $1.0 \mathrm{~mm}$, occurred almost exclusively in the non-cemented group, while cemented components seldom subsided (Mann-Whitney $U$ test; $p<0.001$ ). Varus tilt was sig-

nificantly larger for non-cemented components than for cemented, $0.7^{\circ}$ as compared with $0^{\circ}$ (Mann-Whitney U test, p $<0.03$; Fig. 3).

Unicompartmental tibial components tilted backwards by a mean of $0.7^{\circ}$ while total tibial components tilted forwards by a mean $0.5^{\circ}$ (Mann-Whitney $U$ test, $p<0.002$ ). Unicompartmental components migrated away from the tibial eminence by a mean of $0.5 \mathrm{~mm}$ while total components did not migrate significantly in a mediolateral direction (MannWhitney U test, p $<0.02$; Fig. 4).

In the revision group migration was significantly larger with a mean of $2.7 \mathrm{~mm}$ at 1 year and $3.3 \mathrm{~mm}$ at 2 years (Mann-Whitney U test, $\mathrm{p}<0.001$; Fig. 5). The direction of the migration was greater in varus tilt, outward rotation, anterior tilt, subsidence and anterior translation. There was no difference in mediolateral translation between the two groups.

Fourteen cases had been revised between 2 and 11 years after the initial arthroplasty; continuous migration was found in 13 of them. In the 14th case, the crucial one-year assessment was missing and this case could not be properly assessed. The knee of the 15 th patient was revised during the second year and thus could not be classified. At one year, however, the non-cemented prosthesis had migrated $3 \mathrm{~mm}$, twice the mean for non-cemented implants. The difference in migration between the base and revision groups was also significant when they were split into cemented and non-cemented prostheses. The differences in the proportions of initially and continuously migrating components in the base and the revision materials were also highly significant, $\mathrm{p}<0.0012$ using the SCM criteria and $\mathrm{p}<0.0001$ using the MCM criteria (Fisher's exact test). 
From both groups a total of 131 cases were followed for at least four years and had complete data to allow analysis as to whether long-term migratory behaviour could be identified early. Using the SCM criteria, long-term migration was present in 69 cases; 29 of these had migrated at between one and two years and were identified by RSA at this early stage for a sensitivity of $42 \%$. Sixty-two cases were stable and of these 60 were classified as stable by RSA between one and two years, for a specificity of $97 \%$. The use of MCM criteria for migration increased the sensitivity to $58 \%$ but lowered the specificity to $93 \%$ (Table II).

Table II. Long-term migration using SCM and MCM criteria in 131 cases.

\begin{tabular}{|c|c|c|}
\hline \multirow{2}{*}{$\begin{array}{l}\text { RSA } \\
1 \text { to } 2 \text { years }\end{array}$} & \multicolumn{2}{|c|}{ Long-term migration SCM (MCM) } \\
\hline & Migrating & Stable \\
\hline Migrating $(n=31)$ & $29(25)$ & $2(6)$ \\
\hline Stable $(n=100)$ & $40(18)$ & $60(82)$ \\
\hline Total & $69(43)$ & $62(88)$ \\
\hline
\end{tabular}

With a prevalence of continuous migration in the entire material of $36 \%$, a sensitivity of $58 \%$ and a specificity of $93 \%$, the predictive power, that is the chance that any one individual who is identified by the test at two years will suffer from clinical loosening, was calculated at $82 \%$. Using RSA between 6 months and 1 year as the test, the predictive power was less than $50 \%$.

For 12 of the revisions, the magnitude of the migration at two years was 1SD above the mean for cemented and noncemented cases, respectively, in the base material. Using RSA between one and two years combined with the magnitude of the migration, 12 of the 14 revision cases $(86 \%)$ occurring after the two-year follow-up would have been identified at two years.

When analysing both base and revision groups together, patients with rheumatoid arthritis showed a greater tendency $(p>0.05)$ for continuous migration than those with osteoarthritis. This tendency was significant for continuous migration of more than $0.5 \mathrm{~mm}$ after the one-year followup (chi-squared test, $\mathrm{p}=0.02$ ). With a threshold of $1 \mathrm{~mm}$ the significance was stronger $(p<0.0001)$. Uncemented prostheses showed a similar tendency compared with cemented (chi-squared test; $p=0.04$ ). Age was also related to continuous migration, but only in migration exceeding $1 \mathrm{~mm}$ (Student's $t$-test, $\mathrm{p}=0.014$ ). A two-factor ANOVA test using migration after one year as the dependent variable and age as a covariate factor revealed diagnosis as an independently significant variable $(p<0.01)$ while the type of fixation and age were not. The type of prosthesis was unrelated to migratory pattern (chi-squared test), but pairwise comparison showed the Freeman-Samuelson prosthesis to migrate more after one year. Gender, weight, type of arthroplasty (unilateral or bilateral) and the presence of a stem or metal backing did not affect movement. Of the radiological parameters the hip/knee angle after the operation was linked to continuous migration; a varus knee migrated continuously more often than a knee in valgus (Student's $t$-test, $\mathrm{p}<0.02$ ). Other deviations from the ideal straight leg were not found to be statistically significant.

\section{DISCUSSION}

The most important finding was that all the prostheses which were revised for mechanical loosening could be identified by RSA one to two years after operation, before the onset of symptoms. Mechanical loosening occurred exclusively in prostheses which migrated continuously and of a total of 60 identified in the two groups $12(20 \%)$ became clinically loose. Four other cases have been described which have been revised for loosening, and all migrated continuously (Broström, Goldie and Selvik 1989; Nilsson et al 1991). These prostheses have been of many different types, uncemented and cemented.

Loosening is initiated very early after the arthroplasty, and should not be thought of as a sudden event occurring a number of years after operation, leading to a rapid breakdown of fixation. It represents a prolonged adverse biological process established very early and which after a period, sometimes spanning ten years, becomes of clinical significance. This concept has been suggested in larger patient groups (Grewal, Rimmer and Freeman 1992) and can now be established for individual patients.

Our findings suggest that continuous migration represents defective fixation which becomes established very early, possibly during the operation. In 12 out of 60 cases (20\%) it developed into clinical loosening after a mean of eight years. It is important to establish how soon after arthroplasty continuous migration can be established.

We encountered problems in defining continuous migration in our studies. We used the SCM criteria as the strict standard, but in our earliest cases we had technical problems such as unstable tantalum markers, unstable prostheses, and occasionally missing markers due to faulty radiological projections. We therefore introduced the MCM criteria to represent a more lenient definition, yet one which could differentiate between the two migratory patterns. In this study, the one-year follow-up emerged as an important cut-off point and migration occurring between one and two years proved prognostic. With the SCM criteria the sensitivity was a low $41 \%$ with, however, a high specificity of $97 \%$. Using the MCM criteria, the sensitivity was raised to $58 \%$, while the specificity was lowered to $93 \%$ and the addition of the absolute magnitude of the migration raised the sensitivity to around $85 \%$. Using the MCM data, which is probably more accurate from a practical point of view, RSA between one and two years was established as a test with a reasonable sensitivity and predictive power.

From a technical point of view, segment motion, being a 
composite of a number of point motions, is better defined than point motion. A comparison between point motion and segment motion to differentiate between initial and continuous migration showed agreement in $80 \%$ of the cases. In $10 \%$ segment motion showed stable conditions whereas point motion showed migration, and this was to be expected. In the remaining $10 \%$, point motion showed stable conditions and segment motion showed motion. This is surprising but indicates the difficulty encountered in any measuring system when attempting to find a cut-off point between noise and a true signal. A large number of markers should be used in RSA studies to give high redundancy.

The initial migration occurring during the first year probably represents bone remodelling (Willert, Ludwig and Semlitsch 1974; Vernon-Roberts and Freeman 1976; Draenert 1981). This initial process depends on the mode of fixation and on design factors but appears to be unrelated to future loosening or continuous migration. After one year a large proportion of cases, in which a number of techniques had been used such as cement, non-cement with porous coating, non-cement with immediate interlocking and noncement with titanium mesh and additional screws, remained perfectly stable. It therefore seems that the fixation of these prostheses can function well over long periods of time but with a variable success rate. Cementless immediate interlocking fixation of all-plastic tibial components did poorly.

Other factors may influence continuous migration. Rheumatoid arthritis showed an increased incidence, perhaps due to fatigue exhaustion of the soft rheumatic bone (Hvid 1988). Malalignment has been regarded as an important factor for longevity of knee prostheses (Bargren, Blaha and Freeman 1983; Ecker et al 1987). In this study malalignment in the varus direction proved prognostic while valgus malalignment was rather protective of continuous migration. This finding is somewhat surprising but may be compatible with the fact that the medial condyle is more loaded in the dynamic situation (Morrison 1968). A knee in valgus will counteract this medial overload. Recently, the protective effect of valgus alignment has been shown in a large clinical series (Ritter et al 1994). Age was also prognostic in line with previous studies showing a higher incidence of loosening in younger and presumably more active individuals.

The factors which are responsible for continuous migration and hence loosening are established in the immediate postoperative period. Probably the most decisive time is the operation itself, when a number of factors relating to the patient, the prosthesis and the surgeon are brought to bear on the arthroplasty in a unique combination on each occasion. The fixation problem has recently been thoroughly reviewed (Huiskes 1993) and the contemporary views on the mechanisms of failure condensed into six different patterns, none of which can fully explain the results of our study (Fig. 6).

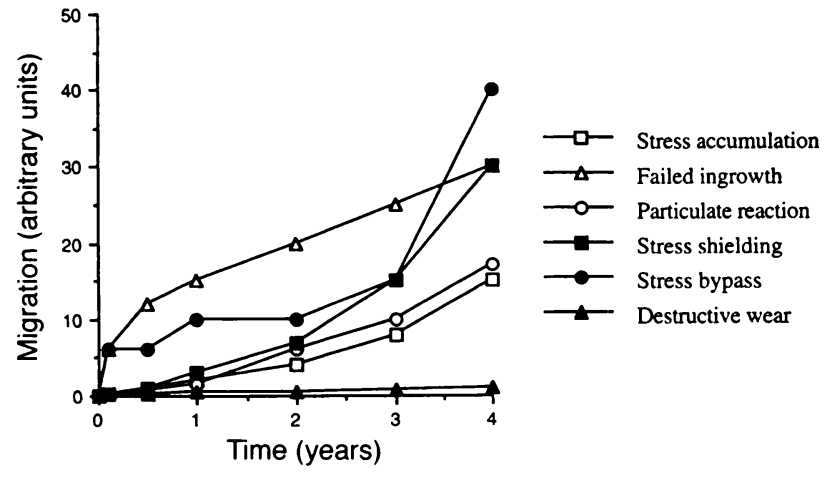

Fig. 6

Hypothetical migratory pattern for prosthetic components failing according to the six scenarios as delineated by Huiskes (1993).

The influence of wear products is of current interest (Goodman, Fornasier and Kei 1988: Howie and VernonRoberts 1988; Willert. Bertram and Buchorn 1990; Goodman and Lidgren 1992; Jones et al 1992), but the evidence in favour of this factor is circumstantial since such debris is also found in the membranes around stable implants (Maloney et al 1990) and it is hard to envisage its presence in sufficient amounts so soon after operation. A multifactorial aetiology for loosening is probable, and wear products may play their role at a later stage than represented in this study. Previous RSA data (Albrektsson et al 1990; Ryd and Toksvig-Larsen 1993) show considerable cyclical motion by which wear products gain access to the interface according to the 'effective joint space' theory (Schmalzried, Jasty and Harris 1992).

We have found that mechanical loosening occurs exclusively in the minority of cases which migrate continuously, and is established within a short time of operation. We do not know if these findings can be applied to implants in other joints, but it has been suggested that loose components in the hip also migrate early and continuously (Mjöberg, Franzén and Selvik 1990; Freeman and Plante-Bordeneuve 1994; Kärrholm et al 1994).

The investigations were financially supported by Greta och Johns Kocks Stiftelse, Stiftelsen Bistånd åt Vanföra i Skåne, Konung Gustav V's 80-årsfond, The Crafoord Foundation. Alfred Österlunds Stiftelse. Nutek, The Medical Faculty of Lund University and the Medical Research Council project 09509 .

No benefits in any form have been received or will be received from a commercial party related directly or indirectly to the subject of this article.

\section{REFERENCES}

Ahlberg A, Lindén B. The radiolucent zone in arthroplasty of the knee Acta Orthop Scand 1977:48:687-90.

Albrektsson BE, Herberts P. ICLH knee arthroplasty: a consecutive study of 108 knees with uncemented tibial component fixation. $J$ Arthroplasty 1988:3:145-56.

Albrektsson BEJ, Ryd L, Carlsson LV, et al. The effect of a stem on the tibial component of knee arthroplasty. J Bone Joint Surg [Br] 1990;72-B:252-8.

Bargren JH, Blaha JD, Freeman MAR. Alignment in total knee arthroplasty: correlated biomechanical and clinical observations. Clin Orthop 1983:173:178-83. 
Blaha JD, Insler HP, Freeman MAR, Revell PA, Todd RC. The fixation of a proximal tibial polyethylene prosthesis without cement. $J$ Bone Joint Surg [Br] 1982;64-B:326-35.

Broström L-Å, Goldie I, Selvik G. Micromotion of the total knee. Acta Orthop Scand 1989;60:443-5.

Cook SD, Thomas KA. Hydroxyapatite-coated porous titanium for use as an orthopedic biologic attachment system. Clin Orthop 1988:230:303-12.

Draenert K. Histomorphology of the bone-to-cement interface: remodeling of the cortex and revascularization of the medullary canal in animal experiments. In: the hip. 9th open scientific meeting of the hip society. St. Louis:CV Mosby, 1981: 71-110.

Ecker ML, Lotke PA, Windsor RE, Cella JP. Long-term results after total condylar knee arthroplasty: significance of radiolucent lines. Clin Orthop 1987:216:151-8.

Freeman MAR, Plante-Bordeneuve P. Early migration and late aseptic failure of proximal femoral prostheses. $J$ Bone Joint Surg $[\mathrm{Br}]$ 1994;76-B:432-8

Geesink RGT, De Groot K, Klein CPAT. Bonding of bone to apatitecoated implants. J Bone Joint Surg [Br] 1988;70-B:17-22.

Goodman S, Lidgren L. Polyethylene wear in knee arthroplasty. Acta Orthop Scand 1992:63:358-64.

Goodman SB, Fornasier VL, Kei J. The effects of bulk versus particulate ultra-high-molecular-weight polyethylene on bone. J Arthroplasty 1988;3:S41-6. [Suppl].

Grewal R, Rimmer MG, Freeman MAR. Early migration of prostheses related to long-term survivorship: comparison of tibial components in knee replacement. J Bone Joint Surg [Br] 1992;74-B:239-42.

Howie DW, Vernon-Roberts B. The synovial response to intraarticular cobalt-chrome wear particles. Clin Orthop 1988;232:244-54.

Huiskes R. Failed innovation in total hip replacement: diagnosis and proposals for a cure. Acta Orthop Scand 1993;64:699-716.

Hvid I. Trabecular bone strength at the knee. Clin Orthop 1988;227:210-21.

Jones SMG, Pinder IM, Moran CG, Malcolm AJ. Polyethylene wear in uncemented knee replacements. J Bone Joint Surg [Br] 1992;74-B:1822.

Kärrholm J, Borssén B, Löwenhielm G, Snorrason F. Early micromotions in cemented femoral stems subsequently revised due to pain or osteolysis. Trans 40th Annual ORS 1994:19:246.

Lidgren L, Bodelind B, Möller J. Bone cement improved by vacuum mixing and chilling. Acta Orthop Scand 1987;58:27-32.

Maloney WJ, Jasty M, Harris WH, Galante JO, Callaghan JJ. Endosteal erosion in association with stable uncemented femoral components. J Bone Joint Surg [Am] 1990;72-A:1025-34.

Miller J, Burke DL, Krause $\mathbf{W}$, et al. Improved fixation of knee arthroplasty components by the injection of acrylic cement into cancellous bone surfaces. J Bone Joint Surg [Br] 1979:61-B:515.

Miura H, Whiteside LA, Easley JC, Amador DD. Effects of screws and a sleeve on initial fixation in uncemented total knee tibial components. Clin Orthop 1990;259:160-8.

Morrison JB. Bioengineering analysis of force actions transmitted by the knee joint. J Biomed Eng 1968;April:164-70.

Mjöberg B, Brismar J, Hansson LI, et al. Definition of endoprosthetic loosening: comparison of arthrography, scintigraphy and roentgen stereophotogrammetry in prosthetic hips. Acta Orthop Scand 1985:56:469-73.

Mjöberg B, Franzén H, Selvik G. Early detection of prosthetic-hip loosening: comparison of low- and high-viscosity bone cement. Acta Orthop Scand 1990;61:273-4.

Nafei A, Nielsen S, Kristensen O, Hvid I. The press-fit Kinemax knee arthroplasty: high failure rate of non-cemented implants. J Bone Joint Surg [Br] 1992;74-B:243-6.
Nilsson KG, Kärrholm J, Ekelund L, Magnusson P. Evaluation of micromotion in cemented vs uncemented knee arthroplasty in osteoarthrosis and rheumatoid arthritis. J Arthroplasty 1991;6:265-78.

Odenbring S, Berggren A-M, Peil L. Roentgenographic assessment of the hip-knee-ankle axis in medial gonarthrosis: a study of reproducibility. Clin Orthop 1993:289:195-6.

Ranawat CS, Rawlins BA, Harju VT. Effect of modern cement technique on acetabular fixation total hip arthroplasty: a retrospective study in matched pairs. Orthop Clin North Am 1989;19:599-603.

Rand JA, Bryan RS, Chaos EYS, Ilstrup DM. A comparison of cemented versus cementless Porous Coated Anatomic total knee arthroplasty. In: Rand JA, Dorr LD, eds. Total arthroplasty of the knee. Proceedings of the knee society 1985-1986. Rockville, Maryland: Aspen Publ Inc 1987;195-212.

Ritter MA, Faris PM, Keating EM, Meding JB. Postoperative alignment of total knee replacement: its effect on survival. Clin Orthop 1994;299:153-6.

Ryd L. Micromotion in knee arthroplasty: a roentgen stereophotogrammetric analysis of tibial component fixation. Acta Orthop Scand 1986;57:Suppl 220

Ryd L, Boegård T, Egund H, et al. Migration of the tibial component in successful unicompartmental knee arthroplasty: a clinical, radiographic and roentgen stereophotogrammetric study. Acta Orthop Scand 1983;54:408-16.

Ryd L, Linder $\mathbf{L}$. On the correlation between micromotion and histology of the bone-cement interface: report of three cases of knee arthroplasty followed by roentgen stereophotogrammetric analysis. J Arthroplasty 1989;4:303-9.

Ryd L, Lindstrand A, Stenström A, Selvik G. Porous coated anatomical tricompartmental tibial components: the relationship between prosthetic position and micromotion. Clin Orthop 1990:251:189-97.

Ryd L, Toksvig-Larsen S. Early postoperative fixation of tibial components: an in vivo roentgen stereophotogrammetric analysis. J Orthop Res 1993:11:142-8.

Schmalzreid TP, Jasty M, Harris WH. Periprosthetic bone loss in total hip arthroplasty. J Bone Joint Surg [Am] 1992;74-A:849-63.

Selvik G. Roentgen stereophotogrammetry. A method for the study of kinematics of the skeletal systems, Thesis, University of Lund Sweden 1974. Reprint in: Acta Arthop Scand 1989;60(Suppl 232).

Snorrason F, Kärrholm J. Early loosening of revision hip arthroplasty: a roentgen stereophotogrammetric analysis. $J$ Arthroplasty 1990;5:217-9.

Søballe K, Hansen ES, Brockstedt-Rasmussen H, et al. Gap healing enhanced by hydroxyapatite coating in dogs. Clin Orthop 1991:272:300-7.

Tibrewal SB, Grant KA, Goodfellow JW. The radiolucent line beneath the tibial components of the Oxford meniscal knee. J Bone Joint Surg [Br] 1984;66-B:523-8.

Toksvig-Larsen S, Ryd L, Lindstrand A. An internally cooled saw blade for bone cuts: lower temperatures in 30 knee arthroplasties. Acto Orthop Scand 1990;61:321-3.

Vernon-Roberts B, Freeman MAR. Morphological and analytical studies of the tissue adjacent to joint prostheses: investigation into the causes of loosening of prostheses. In: Schaldach M, Hohmann D, eds. Advances in artificial hip and knee technology. Berlin, etc: Springer Verlag, 1976;149-85.

Willert HG, Bertram H, Buchorn GH. Osteolysis in alloarthroplasty of the hip: the role of ultra-high molecular weight polyethylene wear particles. Clin Orthop 1990;258:95-107.

Willert H-G, Ludwig J, Semlitsch M. Reaction of bone to methacrylate after hip arthroplasty: a long-term gross, light microscopic, and scanning electron microscopic study. J Bone Joint Surg (Am] 1974:56-A:1368-82 